\title{
Concepções da Prática como Componente Curricular nos Cursos de Licenciatura em Química dos Institutos Federais de Educação, Ciência e Tecnologia
}

\section{Conceptions of Practice as a Curriculum Component in the Undergraduate Courses in Chemistry of the Federal Institutes of Education, Science and Technology (Brazil)}

\author{
Priscila Juliana da Silva \\ Orliney Maciel Guimarães \\ Brasil \\ Brasil
}

Este artigo tem como tema de investigação a Prática como Componente Curricular (PCC) nos cursos de Licenciatura em Química ofertados no Brasil pelos Institutos Federais de Educação, Ciência e Tecnologia. Seu objetivo é analisar as concepções da prática como componente curricular apontadas nos Projetos Pedagógicos de Curso (PPC) das Licenciaturas em Química dos Institutos Federais no Brasil. Como metodologia de pesquisa, utilizou-se da análise documental e definiu-se como fonte de dados os PPC desses cursos. Para responder às questões propostas, este artigo apresenta, a partir de autores que discutem a formação de professores, a constituição desse campo de pesquisa e seus modelos curriculares, bem como as normativas que instituem a PCC. A análise de dados está organizada em três subtópicos, que discutem a organização curricular dos cursos analisados; os conhecimentos priorizados nas disciplinas que desenvolvem a PCC; e os aspectos do campo da formação docente que são expressos nos PPC.

Palavras-chave: Prática como componente curricular; Licenciatura em Química; Formação de professores; Institutos Federais de Educação, Ciência e Tecnologia.

This article has as a research theme the Practice as a Curriculum Component (PCC) in the Undergraduate Courses in Chemistry offered in Brazil by the Federal Institutes of Education, Science and Technology. Its objective is to analyze the conceptions of the practice as a curriculum component pointed out in the Course Pedagogical Projects (CPP) of the Undergraduate Courses in Chemistry of the Federal Institutes in Brazil. As the research methodology, the document analysis was used and the CPP of these courses were defined as data source. To answer the questions proposed, this article presents, authors who discuss teacher training, the constitution of this field of research and its curricular models, as well as the regulations that establish PCC. Data analysis is organized into three subtopics that discuss the curricular organization of the courses 
analyzed; the prioritized knowledge in the disciplines that develop the PCC; and aspects of the field of teacher education that are expressed in CPP.

Keywords: Practice as a curricular component; Undergraduate in Chemistry; Teacher education; Federal Institutes of Education, Science and Technology.

\section{Contextualização da Pesquisa}

A Prática como Componente Curricular (PCC), definida nas Diretrizes Curriculares Nacionais para a Formação de Professores (Resolução n. 01, 2002), tem proporcionado amplas discussões sobre sua finalidade e tem sido organizada em formatos curriculares diversos. Sua diversidade de concepções e práticas demonstra a complexidade da discussão sobre a dimensão prática na formação docente e seu papel, em especial, nas licenciaturas.

As pesquisas sobre a prática como componente curricular têm demonstrado sua potencialidade para redefinir formas de organização dos cursos de licenciatura, mas também dificuldades em planejá-las e explicitá-las nos documentos oficiais. Diante disso, diferentes interpretações da PCC podem também ser realizadas a partir da leitura e implementação das normativas para a formação docente. Por isso, nos Projetos Pedagógicos de Curso (PPC), diversas concepções sobre o objetivo e forma de organização da PCC podem ser apresentados. Portanto, não temos uma única forma de conceber a prática como componente curricular, mas várias. Assim, distintas são as questões que são colocadas neste artigo: De que modo a prática como componente curricular se insere nos projetos pedagógicos de curso das Licenciaturas em Química dos Institutos Federais? Quais as concepções da prática como componente curricular se destacam nesses projetos pedagógicos de curso? Quais conhecimentos são priorizados nas disciplinas que desenvolvem atividades de PCC? Quais princípios do campo da formação docente são assumidos na proposta curricular das atividades de PCC?

A partir das questões norteadoras, apresenta-se como objetivo deste artigo: analisar as concepções da prática como componente curricular apontadas nos projetos pedagógicos de curso (PPC) das Licenciaturas em Química dos Institutos Federais no Brasil. Assim, define-se como metodologia de pesquisa a análise documental, conforme Gil (2008), pois consideram-se como fonte de dados documentos que ainda não receberam tratamento analítico: os projetos pedagógicos de curso (PPC).

Para responder às questões propostas, este artigo apresenta autores que discutem o campo da formação de professores, no período de 1960 até a atualidade, as normativas que orientam a inserção da PCC nos currículos das licenciaturas e os conhecimentos do professor na perspectiva de Shulman (2005). Também é apresentado um tópico com a metodologia utilizada e a análise de dados dividida em 3 subtópicos que discutem a organização curricular dos projetos pedagógicos de curso analisados; os conhecimentos priorizados nas disciplinas que desenvolvem a prática como componente curricular; e os aspectos do campo da formação docente que são expressos nos PPC. 


\section{Concepções da Prática como Componente Curricular na Formação de Professores}

Para auxiliar na análise dos PPC das Licenciaturas em Química ofertadas nos Institutos Federais e da PCC, apresentam-se autores que discutem o campo da formação de professores, no período de 1960 até a atualidade. Esses autores auxiliam na compreensão das mudanças no campo de pesquisa da formação docente que introduzem nas normativas a proposta de curricularização da prática que instituíram a PCC. Ainda, a partir das perspectivas atuais do campo da formação docente, apresentam-se os conhecimentos do professor. Baseando-se nas questões de discussão atuais desse campo, torna-se essencial expor as normativas que orientam a inserção da PCC nos currículos das licenciaturas.

\section{Campo da Formação de Professores}

O campo é um espaço social estruturado cujas propriedades dependem da posição dos agentes nele inserido. Nesse sentido, considera-se que formação de professores, enquanto campo de pesquisa, com objeto próprio, se constitui um campo na perspectiva bourdeusiana. Para elucidar a construção desse campo e suas tendências atuais, apresentam-se as ideias dos seguintes autores: Cunha (2013), Diniz-Pereira (2013), Estevão (2001), Saviani (2009) Contreras (2012) e Marcelo (1998; 1999).

A formação de professores como campo de estudos se constituiu ao longo do tempo com a delimitação de seu objeto de pesquisa e suas formas de investigá-lo. Para Marcelo (1999, p. 26), a formação de professores é uma área do conhecimento e de investigação que "[...] se centra no estudo dos processos dos quais os professores aprendem e desenvolvem sua competência profissional”. Essas formas de investigar se alteram à medida que as relações sociais demandam novas formas de compreender a prática pedagógica e a preparação do professor para sua atuação. Estevão (2001) complementa essa análise e define formação como uma prática social que atua como uma instituição cumprindo funções sociais de regulação e legitimação de valores sociais, por vezes contraditórios. Desse modo, a formação de professores pode ser compreendida a partir da sua trajetória histórica e social. Por isso, a partir do conceito de campo de Bourdieu (1989) e de diferentes autores da formação docente, objetiva-se apresentar o panorama histórico e social da área, especialmente no Brasil, no período de 1960 até os dias atuais.

Diniz-Pereira (2013), a partir de Bourdieu, compreende que um campo se constitui a partir de relações de conflito e/ou aliança dos agentes sociais que lutam pela posse das formas de capitais ou bens materiais e simbólicos valorizados nesse campo. $\mathrm{O}$ autor, ao analisar o campo da formação de professores, mostra as lutas entre diferentes agentes e suas concepções no período de 1970 até 2013, partindo de estudos de diversos autores da área. Assim, Diniz-Pereira (2013) delimita o nascimento do campo da formação de professores em 1973 com a publicação do Handbook of Research on 
Teaching organizado por Robert Peck e James Tucker. Essa publicação possibilitou que a formação de professores adquirisse o status de linha de pesquisa. O autor destaca que já se realizavam pesquisas sobre o tema, mas que até então elas estavam vinculadas a outras temáticas dentro da educação. Portanto, a publicação deste livro, reunindo as pesquisas em torno da formação docente, marca seu surgimento como campo de pesquisa.

Nos anos de 1960 e 1970, esse campo de pesquisa em formação de professores privilegiava a análise da dimensão técnica do trabalho docente. Consequentemente, a formação docente no período se compromete com esses ideais e compreende o professor como:

[...] um organizador dos componentes do processo de ensino-aprendizagem (objetivos, seleção de conteúdos, estratégias de ensino, avaliação, etc.) que deveriam ser rigorosamente planejados para garantir resultados instrucionais altamente eficazes e eficientes. Consequentemente, a grande preocupação, no que se refere à formação do professor, era a instrumentalização técnica (Diniz-Pereira, 2013, p. 146-147).

Nesse período, as pesquisas sobre formação docente divulgadas no Brasil eram em grande parte norte-americanas, de cunho comportamentalista, colocando a eficácia do professor no centro das análises (Cunha, 2013). Compreendia-se que a "[...] competência do professor era avaliada pelo produto, e [...] esse era resultante das condições objetivas do ensino" (Cunha, 2013, p. 5). Assim, "[...] aquele que conseguisse estimular o desenvolvimento de uma aptidão para o máximo de alunos seria igualmente capaz de fazê-los progredir em qualquer outra situação [...] e/ou [...] com qualquer categoria de alunos" (Cunha, 2013, p. 5).

A partir dos anos de 1980, inicia-se um movimento de questionamento da visão tecnicista da formação docente. Em 1982, foi realizado no Rio de Janeiro o I Seminário "A Didática em Questão" em que os pesquisadores da área de didática discutiram os pontos críticos da formação docente, com uma preocupação especial com as licenciaturas, e assumem o compromisso de construir uma didática multidimensional, que articula as dimensões técnica, humana e política. Esse movimento é a gênese de uma grande discussão e produção sobre a formação docente que buscava resgatar o caráter político dos processos pedagógicos com o objetivo de superar o autoritarismo do período de ditadura militar vivenciado pelo país. Nesse período, os estudos privilegiaram os aspectos estruturais e políticos da carreira e da atuação docente. Isso possibilitou uma mudança sobre os objetos de pesquisa da área e assim como no "[...] chão da escola produziam-se movimentos reivindicando maior autonomia dos coletivos institucionais e protagonizando experiências inovadoras, que pretendiam a ruptura com as práticas tradicionais de ensinar e aprender" (Cunha, 2013, p. 7).

Cunha (2013) destaca que novos olhares foram dados à formação docente e o professor passou a ser compreendido não mais como um técnico, mas como um profissional "[...] dentro da estrutura de poder da sociedade, na qual a identidade é concebida como uma construção social e cultural" (Cunha, 2013, p. 6). Ocorre nesse período um deslocamento dos estudos para a compreensão das condições objetivas 
do ensino e dos estudos em que professores e estudantes estavam deslocados de um contexto, assim se passa a compreender esse contexto e suas relações com o processo de ensino.

Nesse cenário, destaca-se que o modelo de formação docente estabelecido no Brasil em 1930, denominado racionalidade técnica, instaura-se a partir do Decreto n. 1.190 de 1939, o qual delineou a estrutura dos cursos de graduação em nível superior. Portanto, a partir dessa normativa, foi iniciado um processo pelo qual os cursos de formação de professores tornaram-se segmentados entre o conhecimento específico e o conhecimento pedagógico, pois, primeiramente, o licenciado cursava disciplinas da área específica de sua formação e, no fim do curso, realizava disciplinas pedagógicas e práticas de ensino. Pesquisas realizadas no campo da formação de professores apontam, até recentemente, que as licenciaturas, no Brasil, eram organizadas neste modelo conhecido como $3+1$, ou seja, três anos de disciplinas específicas e um ano de disciplinas pedagógicas. Tal dualidade é evidenciada por inúmeros autores, entre eles, Saviani (2009) e Marcelo (1999). Esse modelo passa a ser questionado a partir das discussões dos anos de 1980.

O modelo de formação docente proposto pelo 'esquema 3+1' está fundamentado em uma perspectiva acadêmica, que também pode ser denominada 'bacharelizante'. Nesse modelo, conforme postulado por Marcelo (1999), o professor é um especialista em uma área específica. Esses currículos valorizam uma forte formação científica e uma escassa e incompleta formação pedagógica (Marcelo, 1999). Contreras (2012) complementa a análise desse modelo, pois considera que, nessa perspectiva, a prática torna-se apenas a aplicação de conteúdos teóricos e técnicos.

Após esse período de intensas mudanças sociais e políticas dos anos de 1980, nos anos de 1990 alteram os rumos das discussões sobre a formação docente. Dos aspectos macrossociais inicia-se um processo de estudos microssociais. Diniz-Pereira (2013) destaca que nesse período cresceram os estudos sobre o cotidiano escolar, e os saberes docentes e os saberes escolares se constituíram como um objeto de pesquisa constante no país. Esse movimento de estudos microssociais e do uso de metodologias de pesquisa qualitativas avança pelos anos 2000, intensificando as críticas aos programas de formação docente prescritivos, e as pesquisas passam a ter como foco na seguinte pergunta: como nos tornamos educadores? (Diniz-Pereira, 2013).

Para Marcelo (1998), o campo da formação docente tem crescido quantitativamente e qualitativamente e suas preocupações de pesquisa se alteraram da perspectiva da eficiência para questões que envolvem os conhecimentos dos professores, ou seja, como se aprende a ensinar. Cunha (2013) reforça essa ideia, pois compreende que no período de 1990 a 2000 o campo da formação de professores esteve permeado pelas políticas centradas na epistemologia da prática. Para a autora, nessa perspectiva, o professor é um

[...] sujeito reflexivo que toma a prática como ponto de partida da formação e da sua profissionalidade, ressignificando contextualmente a teoria. Assume a autoformação como princípio e a reflexão como possibilidade de desenvolvimento. Considera os 
contextos institucionais e sociais em que atua (Cunha, 2013, p. 12).

A epistemologia da prática, ainda presente e intensa no campo da formação docente, permitiu que esse campo assumisse, a partir dos anos 2000, as narrativas culturais e desenvolvimento profissional como conceitos centrais nas pesquisas. De acordo com Cunha (2013, p.12), nessa perspectiva o professor "[...] age com base nos saberes estruturais, provenientes de diferentes fontes e contextos. Constrói seus saberes a partir das múltiplas influências de formação, em cotejamento com o contexto cultural e institucional onde atua".

Visualiza-se que as alterações no campo da formação docente indicam que há uma mudança epistemológica na organização das licenciaturas e na formação de professores, pois se desloca do modelo da racionalidade técnica, ou 3+1, para um modelo de profissionalização.

Assim, o currículo para a formação inicial precisa ir além dos conhecimentos científicos da área específica, mas promover a apropriação de um "[...] conjunto de comportamentos, conhecimentos, destrezas, atitudes e valores que constituem a especificidade do ser professor" (Nóvoa, 1991, p. 65).

As correntes de pesquisa, que se utilizam da perspectiva dos saberes e conhecimentos do professor, constituem uma abordagem que vem ganhando cada vez mais espaço na pesquisa em educação, e especialmente na formação de professores, a partir de 1980. Neste artigo, optou-se na fundamentação teórica trazer autores que discutem e utilizam o termo conhecimento sobre a prática docente e seus conhecimentos profissionais em suas pesquisas. Essa opção coloca os conhecimentos produzidos na prática pedagógica do professor no mesmo nível dos conhecimentos produzidos na academia, de acordo com Fernandez (2015):

[...] conhecimento é distinto de saber e não é sem razão que Shulman nomeia de "conhecimento de professores" seu programa de pesquisa, pois o que se busca é a valorização da atividade profissional dos professores elevando-a a um espaço de transformação e construção de conhecimentos específicos para a profissão. Assim, o conhecimento é a especialização do saber, ou seja, o conhecimento passa pela reflexão do saber fazer, elevando a prática a um nível de consciência, reflexão, análise, sistematização e intenção. Quando Shulman utiliza a expressão Conhecimento Pedagógico do Conteúdo ao invés de saberes, está realmente igualando o status do que o professor produz na prática (PCK) aos conhecimentos que são produzidos na academia e que influenciam e são influenciados pelo PCK. Tais conhecimentos são os pertencentes à base de conhecimentos - conhecimento do tema, conhecimento pedagógico e conhecimento do contexto, estes sim informados ao professor pela academia. (Fernandez, 2015, p. 504)

Shulman (2005), nos anos de 1980, durante reformas nas políticas para formação de professores nos Estados Unidos, se posiciona em um movimento que pesquisa a prática do professor em um contraponto às pesquisas vigentes. Nesse contexto, o autor pesquisa o que se denomina conhecimento dos professores. Ao observar e analisar a 
prática pedagógica de professores experientes, o autor encontra diversos conhecimentos e suas fontes. Nesse contexto, Shulman (2005) identifica 7 diferentes conhecimentos do professor. O primeiro denominado "Conhecimento do Conteúdo" é o conhecimento específico sobre a disciplina que o professor ensina. O segundo é o "Conhecimento Didático Geral” ou "Conhecimento Pedagógico", que são os princípios e estratégias de organização do ensino que podem ser traduzidas na didática e metodologias de ensino. O terceiro é o "Conhecimento do Currículo", que tem como característica o domínio de materiais e programas de ensino. O quarto é o "Conhecimento dos Alunos", que envolve as características de aprendizagem dos alunos. O quinto é o "Conhecimento dos Contextos Educativos", que abrange o funcionamento da escola, da gestão escolar e das características culturais da comunidade. O sexto é o "Conhecimento dos Fundamentos da Educação", que é o entendimento dos objetivos e valores educativos e seus fundamentos históricos e filosóficos. Por fim, o "Conhecimento Pedagógico do Conteúdo", que pode ser considerado o conhecimento profissional dos professores. Para Shulman (2005, p. 11), esse conhecimento é definido como "[...] esa especial amalgama entre materia y pedagogía que constituye una esfera exclusiva de los maestros, su propia forma especial de comprensión professional".

Esses conhecimentos se constituem a partir de quatro fontes: a formação acadêmica da disciplina que irá ensinar; os materiais e os contextos educativos institucionalizados; os fenômenos sociais e as pesquisas sobre a educação e o desenvolvimento humano; e o conhecimento adquirido na prática. Consequentemente, o conhecimento do professor se constrói na prática pedagógica, constituindo uma elaboração própria de cada profissional. Por isso, a experiência prática se relaciona com a teoria de forma a criar um novo conhecimento que torna a docência um ato de compreensão, raciocínio, reflexão e transformação. Para Shulman,

Tal como hemos llegado a concebir la enseñanza, ella se inicia con un acto de razón, continúa con un proceso de razonamiento, culmina con la acción de impartir, sonsacar, hacer participar, o seducir, y luego es objeto de mayores reflexiones hasta que el proceso puede reiniciarse. En el análisis de la enseñanza que sigue haremos hincapié en la docencia como un acto de comprensión y razonamiento, de transformación y reflexión (Shulman, 2005, p. 17).

O modelo curricular da racionalidade prática, exemplificado acima por meio de Shulman (2005), é denominado por Contreras (2012) de reflexivo, pois articula a ação, ou seja, a prática com a reflexão sobre ela. $\mathrm{O}$ autor considera que, embora a reflexão na ação exija a articulação do ensino com o contexto em que o professor se insere, também tem como limitação uma reflexão estreita a esse contexto micro, não possibilitando ao professor a reflexão sobre as questões sociais e políticas amplas que interferem no trabalho docente. Podemos apontar entre essas questões sociais a carreira docente e as desigualdades sociais.

Contreras (2012) propõe um modelo de formação docente que vai além da reflexão sobre a prática. Esse modelo denominado intelectual crítico compreende a formação 
do professor para a transformação social a partir do conhecimento dos condicionantes sociais e políticos que para serem transpostos exigem a luta coletiva.

$\mathrm{Na}$ discussão de Contreras (2012) sobre formação docente, o autor apresenta a concepção de autonomia profissional do professor em três modelos distintos denominados: 1) Especialista técnico; 2) Profissional Reflexivo; 3) Intelectual Crítico; Para esse autor, perpassam esses modelos de formação docente a autonomia profissional compreendida a partir de visões políticas distintas que estão imbricadas com os processos de mudanças sociais e econômicas. Além disso, para Contreras (2012) três elementos são transversais a profissionalidade docente e se alteram ao longo do tempo em função das questões sociais, econômicas e culturais, e consequentemente impactam o grau de autonomia profissional do professor: 1) A obrigação moral; 2) O compromisso com a comunidade; 3) A competência profissional;

De acordo com Contreras (2012), a natureza da educação e do trabalho docente pressupõe um contrato moral que está acima de qualquer contrato de trabalho. Ensinar exige um compromisso moral com o desenvolvimento dos estudantes, pois consiste em uma relação direta e contínua que visa exercer influência. Dessa forma, a relação pedagógica se constitui a partir do compromisso moral do professor com a aprendizagem dos estudantes ao mesmo tempo em que estabelece com a comunidade uma relação ética de trocas e diálogo, pois a educação como responsabilidade pública obriga a comunidade a participar das decisões sobre o ensino o que torna a prática docente um compromisso social com essa comunidade.

Contreras (2012) compreende que a obrigação moral e a relação com a comunidade se efetiva por meio da competência profissional do professor. Para o autor ensinar exige domínio das metodologias de ensino, dos conhecimentos dos aspectos culturais e conceituais que constituem o objeto de ensino e das competências complexas que entrelaçam habilidades, princípios e consciência do sentido e das consequências das práticas pedagógicas.

Nos três modelos propostos por Contreras (2012) para analisar a formação docente visualiza-se a autonomia profissional de formas distintas. Portanto, o compromisso com a comunidade, a obrigação moral e a competência profissional propostas também se sustentam em princípios diferentes.

No modelo do especialista técnico, a autonomia profissional se constrói a partir do status de autoridade que os conhecimentos específicos de cada área do conhecimento proporcionam aos professores. Contreras (2012) considera essa forma de autonomia profissional ilusória, pois está baseada em diretrizes técnicas das quais o professor é dependente, podendo ainda impedir o desenvolvimento das capacidades de respostas às incertezas e dilemas da sociedade que estão presentes nos espaços formativos. Nesse modelo a técnica é valorizada e o ensino é visto como aplicação. Portanto, ao final de um processo de ensino obtém-se um produto. Assim, na formação de professores esse modelo considera o conhecimento pedagógico e as diferentes metodologias de ensino como meios, mais ou menos, eficientes de ensinar. Contreras (2012) alerta que esse 
modelo de formação não proporciona a autonomia profissional para que o professor tenha a capacidade de tomar as melhores decisões diante das situações de ensino.

O modelo do profissional reflexivo desloca a formação docente dos aspectos técnicos para os aspectos práticos. Portanto, há também uma transferência do processo educativo do professor para o estudante. Dessa forma, a autonomia profissional, para Contreras (2012) se materializa na capacidade individual do professor de resolver as situações problema que impossibilitam a prática educativa, ou interferem na aprendizagem do estudante. Destaca-se nesse modelo a preocupação com a prática pedagógica e sua contínua melhora por meio da reflexão sobre e na ação. Portanto, nesse modelo a limitação que se coloca não é a dificuldade de lidar com as incertezas e complexidades do espaço escolar, mas a reflexão focada apenas na melhoria da prática pedagógica desconsiderando o contexto social e econômico que interfere na vida escolar e, consequentemente, na sala de aula. Ainda pode-se compreender que nesse modelo o professor é o único responsável pelo processo educativo. Assim, a profissionalidade docente se constitui de forma individual e autossuficiente.

Para Contreras (2012) o modelo do professor como intelectual crítico tem como finalidade a formação de um profissional autônomo. Nesse modelo espera-se a emancipação dos professores. Assim, a obrigação moral se edifica em um ensino dirigido para a emancipação individual e social. Por sua vez, o compromisso com a comunidade está na defesa de valores como justiça e igualdade e a participação em movimentos sociais pela democratização. Já a competência profissional se sustenta na reflexão sobre os condicionantes sociais, na análise crítica da realidade social e na participação em ações políticas transformadoras. Portanto, a autonomia profissional é coletiva e se dirige à transformação das condições institucionais e sociais de ensino.

Neste sentido, é necessário para constituir o modelo de formação docente do professor intelectual crítico que a autonomia profissional seja tecida a partir da emancipação e não da autossuficiência, conforme discute Valério:

As chaves da autonomia de professores residem, portanto, em aspectos pessoais (compromissos moral e ético) e sociais (de relacionamento e dos valores que os guiam). Consiste em uma questão humana, não técnica; um elemento educativo, mais que trabalhista; uma qualidade circunstancial de processos e situações, mais que uma característica individual ou psicológica. Existe autonomia na docência quando professores são conscientes de sua insuficiência e parcialidade; quando são solidários e sensíveis com os outros atores do processo, em especial, os estudantes. Essa autonomia, da qual fala Contreras, afasta-se da autossuficiência para se aproximar da emancipação. (Valério, 2017, p. 331)

Visualiza-se que a construção de um modelo de formação docente do intelectual crítico reside na crítica à reflexão como algo imediatista e reducionista, ou seja, focado apenas na melhoria da prática, pois o ensino é uma:

[...] prática social coletiva e também institucionalizada (afetado e/ou condicionado externamente), a criticidade da reflexão deve mirar não apenas a criação de novas ideias 
para o ensino, mas um mergulho do profissional em si e no contexto do fenômeno educativo. Sendo a educação e o ensino ocupações públicas encomendadas pelo coletivo social, a autonomia de professores deve considerar a comunidade como referência e como corresponsável pelas condições em que ocorrem. De modo exemplar, professores deveriam tomar consciência de que estratégias técnicas (metodologias) não podem ser analisadas apenas pelo mérito (ser ou não eficaz), mas pelo que representam como pretensões e razões educativas (Valério, 2017, p. 331).

Embora se compreenda as contribuições da racionalidade prática para a formação docente, especialmente, pela valorização da dimensão prática do conhecimento, é preciso ponderar a ausência dos aspectos sociais e políticos essenciais a uma formação crítica. Essa ponderação se torna mais urgente ao considerarmos as normativas para a formação docente no Brasil, pois elas são influenciadas pelos modelos de formação docente da racionalidade prática. Assim, pode-se compreender, a partir da racionalidade prática, que a Prática como Componente Curricular pode assumir o papel de profissionalização do professor desde o início do curso de licenciatura, pois pode aproximar o licenciando do contexto da profissão docente. Além disso, essa prática pode, em sua organização curricular, articular diferentes conhecimentos que compõe os currículos da licenciatura. Portanto, a PCC como conhecimento tem a potencialidade de promover a relação teoria e prática ao longo de todo processo formativo inicial do licenciando. Entretanto, em um país marcado pela desigualdade social, é essencial que a PCC considere em suas articulações as dimensões sociais e políticas da educação, incentivando os licenciandos a desenvolver um pensamento crítico sobre a realidade, a qual permita que ele desenvolva uma prática pedagógica transformadora. Nesse sentido, considera-se que os pareceres que discutem a PCC e a Resolução n. 2 de 2015 apesar de apresentarem avanços importantes para o campo da formação de professores e para a organização curricular das licenciaturas, não incentivam ou promovem uma formação crítica dos licenciandos que atuarão em uma realidade social e educacional complexa.

\section{A Prática como Componente Curricular na Legislação}

Inserida nos processos sociais e econômicos que possibilitaram a emergência da racionalidade prática e, consequentemente, no modelo do profissional reflexivo, a PCC surge na legislação para a formação docente em 2002 quando entraram em vigor as Resoluções do Conselho Nacional de Educação, 01 e 02 de 2002, que definem as diretrizes nacionais para a formação de professores para a Educação Básica e a carga horária dos cursos de licenciatura. Essas diretrizes de 2002 foram recentemente atualizadas pela Resolução $\mathrm{n}^{\circ} 2$ de 2015, que busca maior organicidade à formação de professores para a Educação Básica, unindo em um mesmo documento a formação inicial e continuada de professores (Dourado, 2015).

Essas normativas citadas assumem como objetivo a consolidação de um novo modelo de formação docente a partir do modelo da racionalidade prática, que tem como principal característica a articulação dos conhecimentos específicos e pedagógicos para a 
construção da profissionalidade docente. Portanto, os cursos de licenciaturas não devem se confundir com o bacharelado, mas ter uma identidade própria. Nesse cenário, a PCC é incentivada como forma de garantir que a articulação entre teoria e prática ocorra ao longo de toda a formação do licenciando. A valorização da prática surge nas normativas como uma forma de desenvolver competências e habilidades dos licenciandos para atuar na Educação Básica, portanto as articulações possíveis pelas orientações das normativas se baseiam no modelo do professor reflexivo proposto por Contreras (2012), logo pode apresentar limitações desconsiderando na reflexão o contexto social e econômico que interfere no cotidiano escolar. Essa visão reducionista pode ser encontrada no Parecer n. 15 de 2005 que considera a PCC como experiências de aplicação de conhecimentos, ou seja, colocar em uso o conhecimento.

Conforme o Parecer n. 15 de 2005, que esclarece aspectos sobre a Resolução n. 02 de 2002, Prática como Componente Curricular é definida como:

[...] o conjunto de atividades formativas que proporcionam experiências de aplicação de conhecimentos ou de desenvolvimento de procedimentos próprios ao exercício da docência. Por meio destas atividades, são colocados em uso, no âmbito do ensino, os conhecimentos, as competências e as habilidades adquiridos nas diversas atividades formativas que compõem o currículo do curso. As atividades caracterizadas como Prática como Componente Curricular podem ser desenvolvidas como núcleo ou como parte de disciplinas ou de outras atividades formativas. Isto inclui as disciplinas de caráter prático relacionadas à formação pedagógica, mas não aquelas relacionadas aos fundamentos técnico-científicos correspondentes a uma determinada área do conhecimento (Parecer n. 15, 2005, p.3).

De acordo com o Parecer n. 15 de 2005, percebe-se que as normativas compreendem que a PCC deve estar presente na formação do licenciando ao longo de todo curso de licenciatura. Essa interpretação é reafirmada por Mohr, e Pereira (2017), que ao analisarem os documentos legais que normatizam a PCC, concluem que ela precisa ser organizada ao longo de todo curso por meio de atividades que não incluem obrigatoriamente estar no espaço escolar, mas que promovam reflexões sobre a prática pedagógica. Portanto, as autoras defendem que as normativas para formação docente compreendem a PCC como uma preparação para a prática docente ao longo de todo processo formativo inicial, rompendo com a ideia de que o estágio é reservado à prática, enquanto a sala de aula é o espaço da teoria. Nesse sentido, reforça-se que a PCC tem potencialidades para articulações entre conhecimentos e entre a teoria e a prática que são fundamentais para a formação docente.

A partir dessa interpretação da PCC, apresentada por Mohr, e Pereira (2017), ela não deve ser confundida com o estágio obrigatório, pois esse exige o desenvolvimento da prática no espaço escolar. Essa distinção entre PCC e estágio obrigatório é discutida no Parecer n. 28 de 2001 que define o estágio curricular supervisionado como uma forma de atividade de capacitação em serviço e que só pode ocorrer em unidades escolares, onde o estagiário assuma o papel de professor, sendo o momento de efetivação do processo 
de ensino-aprendizagem desenvolvido ao logo da formação nos cursos de licenciatura (Parecer n. 28, 2001).

Real (2012), ao analisar as normativas que definem a PCC, argumenta que a mesma enquanto componente curricular tem um espaço próprio no currículo, que se distingue do estágio supervisionado e que estabelece um eixo de integração entre a dimensão teórica e a atividade profissional docente. Assim, a PCC não necessita ocorrer na escola, mas pode ser contextualizada na realidade escolar inclusive com o uso de tecnologias.

As compreensões da PCC e suas distinções do estágio curricular, ou mesmo sua distinção das práticas experimentais exigidas pelas áreas específicas, como é o caso da Química, se apresentam como desafios diante da construção dos PPC. Ao mesmo tempo, defende-se que a PCC, como curricularização da prática, pode constituir um espaço formativo inicial para os professores, rompendo com o modelo da racionalidade técnica ao articular a teoria e a prática e se tornar um espaço de desenvolvimento dos conhecimentos do professor, articulando os conhecimentos específicos e pedagógicos $\mathrm{com} / \mathrm{para} /$ na a prática pedagógica. Consequentemente, reforça-se que os pareceres que discutem a PCC e a Resolução no 2 de 2015 apresentam avanços importantes para o campo da formação de professores e para a organização curricular das licenciaturas mesmo que estejam marcadas por concepções da racionalidade prática.

\section{Metodologia}

A pesquisa qualitativa em educação, de acordo com Minayo (2015), se propõe a responder questões particulares do mundo social, desenvolvendo suas investigações a partir dos significados, motivos, valores, aspirações e crenças do ser humano. São características dessa forma de pesquisa o ambiente ou realidade social como fonte direta de dados, a preocupação com a descrição dos significados, a preocupação com o processo e não com o produto e o uso do raciocínio indutivo na forma de análise (Triviños, 1987). Isso significa que a pesquisa qualitativa articula teoria e dados empíricos partindo da realidade social e considerando a prática como expressão da teoria. Diante desses fundamentos, a escolha dos procedimentos metodológicos se apoia na natureza do objeto de pesquisa e o seu objetivo, pois os recortes da realidade na pesquisa qualitativa podem ser diversos e seus fundamentos permitem a apropriação de diferentes métodos (Flick, 2009). Portanto, a pesquisa qualitativa é considerada um trabalho artesanal que constrói uma linguagem e um ritmo (Minayo, 2015).

Diante do objetivo proposto por esse artigo, da natureza de seu objeto e dos fundamentos da pesquisa qualitativa apresentados, caracteriza-se essa pesquisa como documental, pois, conforme Gil (2008), sua fonte de dados são documentos produzidos por diferentes instituições que ainda não receberam tratamento analítico: os projetos pedagógicos de curso (PPC).

Nessa perspectiva, considera-se documento qualquer objeto, escrito ou não, que possa contribuir com a investigação de um fenômeno (Gil, 2008). Neste estudo, 
os documentos analisados são escritos e considerados fonte primária, pois não foram criados no contexto da pesquisa, mas em um contexto social específico que foi examinado a partir das informações de contextos fornecidas pelo documento.

O primeiro passo desta pesquisa foi o levantamento dos cursos de Licenciatura em Química ofertados pelos Institutos Federais de Educação, Ciência e Tecnologia (IFEs) em todas as regiões do Brasil por meio de consulta ao portal E-Mec. Esse portal alimentado pelo Ministério da Educação (MEC) disponibiliza dados de cursos superiores em todo país. No acesso ao E-Mec foram localizados 82 cursos de licenciaturas em Química ofertadas nos IFEs em todo país, distribuídas nas diferentes regiões e estados. Em seguida, se iniciou a busca pelos PPC nos portais de cada instituição na internet. Não foram localizados 24 PPC, então foi realizado contato por e-mail com esses institutos tentando ter acesso a esses projetos não localizados nos sítios eletrônicos dessas instituições e obteve-se os documentos de outros 7 institutos. Portanto, a análise foi realizada com 65 projetos pedagógicos de curso, o que corresponde a 79,27\% dos cursos de Licenciatura em Química ofertados nos IFEs do país, conforme dados da Tabela 1.

Tabela 1. Número de Licenciaturas em Química e Projetos Pedagógicos de Curso Localizados e Analisados

\begin{tabular}{lcccccc}
\hline \multirow{2}{*}{ Região } & \multicolumn{2}{c}{ PPC Localizados } & \multicolumn{2}{c}{ PPC Não Localizados } & \multicolumn{2}{c}{ Total de Cursos } \\
\cline { 2 - 7 } & No & $\mathbf{\%}$ & $\mathbf{N}^{\mathbf{0}}$ & $\mathbf{\%}$ & $\mathbf{N}^{\mathbf{2}}$ & $\mathbf{\%}$ \\
\hline Centro-Oeste & 11 & 13,41 & 3 & 3,66 & 14 & 17,07 \\
\hline Nordeste & 25 & 30,49 & 9 & 10,98 & 34 & 41,46 \\
\hline Norte & 4 & 4,88 & 1 & 1,22 & 5 & 6,10 \\
\hline Sudeste & 12 & 14,63 & 2 & 2,44 & 14 & 17,07 \\
\hline Sul & 13 & 15,86 & 2 & 2,44 & 15 & 18,29 \\
\hline Total & $\mathbf{6 5}$ & $\mathbf{7 9 , 2 7}$ & $\mathbf{1 7}$ & $\mathbf{2 0 , 7 3}$ & $\mathbf{8 2}$ & $\mathbf{1 0 0 , 0 0 \%}$ \\
\hline
\end{tabular}

A análise dos Projetos Pedagógicos de Curso (PPC) foi realizada em três etapas. Primeiramente, foi realizada a leitura de todos os PPC com o objetivo de encontrar no texto, na matriz curricular e nas ementas as concepções e formas de organização da Prática como Componente Curricular. Assim, organizaram-se dois quadros. O primeiro com as disciplinas em que a PCC está presente e a sua respectiva ementa. O segundo com as citações textuais sobre a PCC de cada um dos PPC. Em seguida, realizou-se a leitura desses dados para buscar as concepções expressas nos princípios orientadores definidos para a PCC no PPC, bem como os conhecimentos priorizados nas ementas. Por fim, organizou-se o texto de análise que apresenta as concepções com maior incidência nos PPC e as articulações dos diferentes conhecimentos na organização curricular.

Para apresentar os elementos textuais de cada projeto pedagógico de curso, foi elaborado um sistema de siglas que garante o anonimato da instituição. Dessa forma, os 65 PPC são nomeados de acordo com a região do país, conforme os seguintes exemplos: IF-Norte-1; IF-Sul-29 e IF-Sudeste-45. Nessa forma de nomenclatura, optou-se por uma numeração contínua do 1 ao 65, mantendo a sigla IF seguida da região de oferta do curso. 


\section{Concepções da Prática como Componente Curricular nos Projetos Pedagógicos de Curso}

As concepções da PCC nos cursos de Licenciatura em Química são apresentadas em três tópicos, nas subseções a seguir.

\section{Organização Curricular da Prática como Componente Curricular}

Considera-se que a Resolução n. 02 de 2015 avançou em relação às Resoluções n. 01 e 02 de 2002 ao aumentar a carga horária total dos cursos de licenciatura e o tempo mínimo de integralização do curso pelos licenciandos para 4 anos ou 8 semestres, portanto é pertinente apresentar as diferenças entre as resoluções e de que modo essas distinções se inserem nos PPC analisados.

A carga horária dos cursos de licenciatura definida na Resolução n. 02 de 2015 é dividida em 400 horas de PCC, 400 horas de estágio supervisionado, 200 horas de atividades complementares, com viés teórico-prático, e 2200 horas de formação geral que compreende as áreas específicas e interdisciplinares, e do campo educacional, seus fundamentos e metodologias, e das diversas realidades educacionais e o núcleo de aprofundamento e diversificação de estudos das áreas de atuação profissional que inclui conteúdos específicos e pedagógicos. Dessa forma, a partir dessa resolução, a carga horária mínima total para os cursos de licenciatura é de 3200 horas. Por sua vez, a normativa anterior, Resolução n. 02 de 2002, definia 1800 horas de conteúdos científicos e culturais acrescidas de 400 horas de PCC, 400 horas de estágio supervisionado, 200 horas de atividades complementares totalizando 2800 horas totais.

Considerando que os PPC analisados têm como recorte temporal o período de 2005 até 2018, essas diferenças na carga horária foram percebidas na análise dos projetos pedagógicos de curso, pois se verificou que a carga horária total dos cursos de Licenciatura em Química varia em 2800 e 4000 horas. Tal variação se justifica em função do ano em que os PPC foram aprovados, pois até a publicação da Resolução n. 02 de 2015 era exigida pela legislação o mínimo de 2800 horas de carga horária total dos cursos de licenciatura e a partir de 2015 essa exigência passou para 3200 horas. Destaca-se que a Resolução n. 03 de 2018 alterou o artigo 22 da Resolução n. 02 de 2015, permitindo aos cursos de licenciatura a adequação as novas diretrizes em até 4 anos. Portanto, apesar das diferenças de cargas horárias, os cursos analisados estavam no prazo legal para realizar as alterações.

Diante dessa consideração, depreende-se que todos os PPC aprovados a partir de 2015 têm carga horária total a partir de 3200 horas, e mesmo no período anterior há diversos PPC que apresentam carga horária a partir de 3200 horas. Do total de 65 PPC analisados, 22 apresentaram carga horária menor que 3200 horas, ou seja, 34\% dos cursos deverão passar por reestruturação para atender a Resolução n. 02 de 2015. Desse total de 43 PPC, 66\%, apresentaram carga horária igual ou superior a 3200h. Assim, destaca-se que a Resolução n. 02 de 2015 poderá promover mudanças significativas nos 
cursos de licenciatura ao aumentar a carga horária das licenciaturas.

Em relação à carga horária de PCC (Tabela 2) a legislação não promoveu alterações e a maioria dos PPC prevê 400 horas dessas atividades. Entretanto, há 19 PPC (30\%), que têm uma carga horária entre 420 e 596 horas, sendo três com carga horária acima de 500 horas. Também se constatou que há dois PPC que não apresentam a carga horária de PCC, embora apresentem no texto a sua inserção no curso. Destaca-se um PPC de 2011 que tem 370 horas de PCC.

Tabela 2. Carga Horária das Licenciaturas em Química nos Projetos Pedagógicos de Curso Analisados

\begin{tabular}{ccccccc}
\hline \multicolumn{2}{c}{ Carga Horária Total do Curso } & \multicolumn{4}{c}{ Carga Horária de PCC } \\
\hline $\begin{array}{c}\text { Menor que } \\
\text { 3200h }\end{array}$ & $\begin{array}{c}\text { Igual ou Superior } \\
\text { a 3200 h }\end{array}$ & Total & $\begin{array}{c}\text { Menor que } \\
\mathbf{4 0 0 h}\end{array}$ & $\begin{array}{c}\text { Igual ou } \\
\text { Superior 400h }\end{array}$ & $\begin{array}{c}\text { Sem Carga } \\
\text { Horária }\end{array}$ & Total \\
\hline 22 & 43 & $\mathbf{6 5}$ & 1 & 62 & 2 & $\mathbf{6 5}$ \\
\hline $33,85 \%$ & $66,15 \%$ & $\mathbf{1 0 0 \%}$ & $1,54 \%$ & $95,38 \%$ & $3,08 \%$ & $100 \%$ \\
\hline
\end{tabular}

Conforme o Parecer n. 15 de 2005 as PCC:

[...] podem ser desenvolvidas como núcleo ou como parte de disciplinas ou de outras atividades formativas. Isto inclui as disciplinas de caráter prático relacionadas à formação pedagógica, mas não aquelas relacionadas aos fundamentos técnico-científicos correspondentes a uma determinada área do conhecimento. (Parecer n. 15, 2005, p. 3 )

A partir dessa definição de PCC, sinaliza-se que ela deverá estar nas atividades formativas dos cursos de licenciatura em todos os componentes curriculares, exceto, como no caso da Licenciatura em Química em atividades técnico-científicas próprias da área. O Parecer 28 de 2001 também compreende a PCC como uma dimensão do conhecimento que deve estar presente nas licenciaturas "[...] nos momentos em que se trabalha na reflexão sobre a atividade profissional, como durante o estágio, nos momentos em que se exercita a atividade profissional" (Parecer n. 09, 2001, p. 22).

Nos PPC citados abaixo, a PCC está inserida em grande parte das disciplinas ao longo do curso. Visualiza-se que, em alguns trechos, especifica-se que o estágio e aulas de laboratório não terão carga horária para desenvolver PCC, atendendo as prerrogativas das normativas sobre a PCC. Em alguns PPC a opção de inserir a PCC nas diversas disciplinas no curso não está explícita no texto, mas se apresenta na distribuição de carga horária na matriz curricular. Salienta-se que essa forma de organização compreende a prática como eixo transversal ao curso, que se desenvolve durante toda a formação profissional, como saberes articulados a todas as demais áreas do conhecimento.

IF-Centro-Oeste-1: Todas as disciplinas, exceto o Estágio Supervisionado e aulas de Laboratório, contemplarão a PCC, sob a orientação do professor. (2014, p. 32)

IF-Nordeste-28: A prática como componente curricular envolve as atividades de ensino, pesquisa e extensão voltadas para o ensino da Química, devendo ser contempladas durante todo o Curso. (2013, p.44) 
IF-Norte-38: A PCC deve ser desenvolvida ao longo do processo de formação do acadêmico. Sob este entendimento, no curso de Licenciatura em Química [...] a PCC constitui-se em atividades que permeiam determinados componentes curriculares conforme quadro a seguir, os quais destinam um percentual da carga-horária total para atividades relacionadas ao exercício da docência. (2011, p. 131)

IF-Sudeste-47: Desse modo, optou-se por fazer a distribuição dessas 412 horas em disciplinas específicas e pedagógicas, ao longo de todos os semestres. (2014, p. 30)

IF-Sul-61: A Atividade Prática como Componente Curricular são atividades voltadas à prática pedagógicas distribuídas ao longo dos quatro anos letivos do curso de Licenciatura em Química. (2016, p. 82)

A partir dessas reflexões, destaca-se que a PCC precisa estar presente em toda a formação do licenciando. Assim, a organização curricular dos PPC das Licenciaturas em Química foi analisada a partir de três elementos: forma de inserir a PCC na matriz curricular, nome dado a PCC e os conhecimentos priorizados no desenvolvimento da PCC. Dessa forma, se constatou nos PPC quatro formas de inserir a PCC na matriz curricular. A com maior incidência distribui as 400 horas de PCC em diversas disciplinas, sendo uma porcentagem da carga horária de cada uma das disciplinas. A segunda forma com maior incidência insere no currículo disciplinas específicas que tem toda sua carga horária para desenvolver a PCC. Com menor incidência, a terceira forma contempla as duas formas anteriormente citadas, a qual se denomina de híbrida. Essas formas de organização curricular da PCC, e sua incidência nos PPC, visualizam-se na Tabela 3.

Tabela 3. Inserção da PCC nos Projetos Pedagógicos de Curso

\begin{tabular}{lcc}
\hline Formas de Inserir a PCC na Matriz Curricular & Número de PPC & \% \\
\hline Em diversas disciplinas da matriz curricular & 28 & 43,08 \\
\hline Disciplinas específicas criadas para desenvolver atividades de PCC & 25 & 38,46 \\
\hline Forma Híbrida & 7 & 10,77 \\
\hline Forma Indefinida de Organização da PCC & 5 & 7,69 \\
\hline Total & 65 & 100,00 \\
\hline
\end{tabular}

O modelo que insere a PCC em diversas disciplinas apresenta um grau de incerteza sobre o desenvolvimento da PCC, visto que não explora na ementa ou no texto do PPC como essas atividades são desenvolvidas. Assim, é possível que apenas tenha sido incluída a carga horária de PCC nessas disciplinas para atender a legislação sem preocupação com a discussão pedagógica e/ou mudança de concepção de formação docente que a dimensão prática poderia proporcionar para o modelo de formação dos professores do intelectual crítico proposto por Contreras (2012).

Essas diferentes formas de inserir a PCC nos PPC das Licenciaturas em Química mostram o aumento da dimensão prática incentivada pelas normativas para formação docente e a possibilidade de construção de cursos alinhados na perspectiva da racionalidade prática. 
De acordo com os PPC citados abaixo, a PCC foi inserida na matriz curricular por meio de disciplinas específicas que tem toda sua carga horária voltada para seu desenvolvimento. Em alguns PPC essas disciplinas têm denominações que envolvem várias nomenclaturas como, por exemplo, instrumentação, prática pedagógica, oficina de prática pedagógica, prática de ensino, prática educativa, etc.

Além das distintas nomenclaturas, destaca-se o PPC do IF-NORDESTE-28 que apresenta em sua proposta de PCC um modelo curricular contextualizado e crítico próximo ao modelo do intelectual crítico proposto por Contreras (2012). Assim, surge a possibilidade da PCC promover articulações entre teoria e prática que se fundamentam no modelo do intelectual crítico, pois ao desvelar os condicionantes institucionais e sociais da prática pedagógica podem-se visualizar respostas coletivas para resolvê-los e não apenas soluções imediatistas e focadas na técnica.

IF-Centro-Oeste-5: Oficinas Pedagógicas (OPP's) e na Instrumentação para o Ensino de Química. A seguir é especificada a carga horária destinada à prática como componente curricular no curso de Licenciatura em Química [...]. 2 Período: Oficina de Prática Pedagógica de Química Geral $(68$ h); 3 Período: Instrumentação Para o Ensino de Química (68 h), Oficina de Informática Aplicada ao Ensino de Química (68 h); 4 Período: Oficina de Prática Pedagógica de Química Analítica (68 h); Prática Pedagógica de Química Orgânica (68 h); 7 o Período: Oficina de Prática Pedagógica de Físico-Química (68 h). (2018, p. 21)

IF-Norte-40: A Prática como componente curricular é realizada através da disciplina Prática Educativa ofertada desde o primeiro semestre, até o oitavo semestre. (2016, p.81)

IF-Sudeste-50: A Prática como Componente Curricular será ministrada como Práticas Pedagógicas (I a VI), abrangendo 405 horas distribuídas do $3^{\circ}$ ao $8^{\circ}$ período do curso, permeando a formação do professor. (2010, p. 23)

IF-Nordeste-28: De forma mais específica, os componentes curriculares de Prática de Ensino da Química I, II, III e IV (do $1^{\circ}$ ao $4^{\circ}$ período) e os componentes curriculares de TCC I e II (nos $7^{\circ}$ e $8^{\circ}$ períodos) visam construir juntos aos licenciandos o conhecimento pedagógico do conteúdo, estando esses componentes curriculares inseridos em três dimensões fundamentais: (I) o contexto social, o qual, além de outras questões, sugere-se abordar a discussão da relação Educação-Trabalho; (II) o contexto da escola, o qual possibilita compreender a relação escola-sociedade, assim como os arranjos institucionais e organizacionais internos, e (III) o contexto da aula, que trabalha os ambientes de aprendizagem e culmina no estágio curricular supervisionado propriamente dito (2013, p. 45)

IF-Centro-Oeste-11: Práticas de ensino (400 h/r): as práticas de ensino serão divididas em seis dos oitos semestres do curso, perfazendo um total de seis disciplinas de 67 horas/a cada, distribuídas do segundo ao oitavo semestre; (2014, p. 15)

Ao analisar a distribuição das disciplinas específicas, em que a PCC foi inserida na matriz curricular em disciplinas com toda sua carga horária voltada para 
seu desenvolvimento, visualizou-se que dos 25 PPC apenas 10 distribuem na matriz curricular essas disciplinas de modo a contemplar todo o processo formativo conforme previsto na Resolução n. 02 de 2015. Entre os PPC que não alocaram a PCC ao longo dos cursos destacam-se que 2 PPC dividem as 400 horas em apenas duas disciplinas, 10 PPC alocaram as 400 horas em 6 disciplinas e 3 PPC em 7 disciplinas. Nas citações acima, alguns PPC se destacam por não contemplarem a PCC em todo o curso de licenciatura: IF-Sudeste-50, IF-Nordeste-28 e IF-Centro-Oeste-11.

Entre as diferentes formas de organização da PCC nos PPC dos cursos de Licenciatura em Química foi possível identificar 5 que apresentam em seu texto princípios para o desenvolvimento dessas atividades e, em 4 deles, a carga horária. Entretanto, não foi possível visualizar na matriz curricular ou nas ementas a organização das atividades de PCC. Esses cursos são os seguintes: IF-Nordeste-16, IF-Norte-39, IFSudeste-41, IF-Sudeste-42 e IF-Sul-6. Nesse sentido, as reestruturações curriculares que serão promovidas pela Resolução n. 02 de 2015 podem alterar esse cenário.

Destaca-se que foram identificados 7 PPC que organizam as atividades de PCC de forma híbrida, ou seja, tem a carga horária distribuída em diversas disciplinas da matriz curricular, mas também em algumas disciplinas específicas em que apenas a PCC é desenvolvida na integralidade da carga horária e/ou ementa. Esses cursos são os seguintes: IF-Centro-Oeste-6, IF-Norte-38, IF-Sudeste-45, IF-Sudeste-46, IF-Sudeste-52 IF-Sul-53, e IF-Sul-58.

Em um estudo similar ao deste artigo, Almeida (2016) analisou 18 cursos de Licenciatura em Química no estado de Goiás. Nesses cursos 40\% organizaram a PCC em disciplinas tradicionalmente ofertadas que envolvem conhecimentos pedagógicos e conhecimentos técnico-científicos da área específica de Química. Por sua vez, 22\% desses cursos optaram por inserir disciplinas novas na matriz curricular com o objetivo exclusivo de desenvolver as atividades de PCC. A autora ainda identificou que 5\% dos cursos se organizam de modo híbrido, ou seja, com a PCC em disciplinas já existentes nos cursos de licenciatura e com disciplinas novas criadas para desenvolver atividades de PCC. Destaca-se que 33\% dos PPC não apresentaram clareza na forma de inserir ou organizar as atividades de PCC no curso.

Ao compararmos os resultados do estudo de Almeida (2016) com os dados apresentados acima, observa-se que as formas de organizar a PCC se repetem em nível nacional e que a porcentagem de PPC que não apresentam clareza na forma de organizar essas atividades diminui, correspondendo a 7,69\% dos PPC analisados.

Por fim, sobressai-se na análise da organização curricular dos PPC analisados a potencialidades das normativas para a formação docente, pois se visualiza que a curricularização da prática por meio da PCC possibilitou que os cursos de Licenciatura em Química analisados promovessem maiores articulações entre teoria e prática. Assim, considera-se que os PPC estão em consonância com as concepções da racionalidade prática propostas pelas normativas para formação docente, e consequentemente, abrem caminhos para romper com a predominância da racionalidade técnica. 


\section{Os Conhecimentos Priorizados nas Disciplinas que Desenvolvem a Prática como Componente Curricular}

Com o objetivo de compreender a organização dos conhecimentos no PPC, as ementas de disciplinas que estavam previstas para atender a carga horária de PCC foram analisadas. Assim, dos 65 PPC analisados, 28 foram classificados em sua organização curricular como distribuindo a PCC em diversas disciplinas. Desses vinte e oito PPC, os 22 que deixaram explícitos as disciplinas que contemplam a PCC foram analisados individualmente. Também foram analisados os PPC que organizaram a PCC de forma híbrida. Do total de 7 PPC, 6 foram analisados, pois em um PPC não foi possível classificar a organização do conhecimento, pois não apresentaram as ementas no PPC. Essa dificuldade de explicitar nos PPC, e de colocar em quais disciplinas e quais os conteúdos que serão desenvolvidos nas disciplinas de PCC, também aparece no estudo de Kasseboehmer, e Farias (2012) que, ao analisarem as disciplinas que desenvolvem atividades de PCC em 25 cursos de Licenciatura em Químicas das regiões Norte e Sudeste do Brasil, perceberam que metade destes não explicita como desenvolve ou organiza as atividades de PCC.

Dos 22 PPC que organizam a carga horária de PCC ao longo de todo curso, 7 apresentam nas ementas frases padronizadas sobre a PCC. A seguir são apresentadas duas dessas citações padronizadas, pois o trecho que aparece no PPC do IF-Nordeste-17 é idêntico aos seguintes PPC: IF-Nordeste-18, 19 e 20. Já a citação do IF-Sudeste-49 também aparece nos PPC dos IF-Sudeste-47 e 51:

IF-Nordeste-17: Na prática enquanto componente curricular do ensino será avaliada a capacidade do estudante fazer a transposição didática, ou seja, transformar determinada temática em um produto ensinável. (2017, p. 52)

IF-Sudeste-49: Relaciona, através da prática como componente curricular, os conhecimentos em Química Geral com atividades formativas que promovam experiências e reflexões próprias ao exercício da docência. (2014, p. 50)

Ao classificar os conhecimentos desenvolvidos nas disciplinas e suas cargas horárias de PCC, definiram-se os conhecimentos tendo como parâmetros os conhecimentos do professor propostos por Shulman (2005) e também aqueles presentes na Resolução n. 02 de 2015. Salienta-se que essa é uma organização realizada no processo de pesquisa e que os PPC não obrigatoriamente organizaram os conhecimentos na perspectiva de Shulman (2005). Desse modo, foram consideradas todas as disciplinas gerais que desenvolvem conhecimentos diversos das seguintes áreas: física, matemática, linguagem, tecnologias, metodologia de pesquisa e filosofia da ciência. Por sua vez, as disciplinas específicas são aquelas que tratam de conhecimentos da química. Já nas disciplinas pedagógicas foram consideradas todas aquelas que envolvem os processos educativos por meio da didática, políticas públicas educacionais, fundamentos sociais e filosóficos da educação e psicologia do desenvolvimento e da aprendizagem. Destacam-se na classificação realizada as disciplinas articuladoras que desenvolvem o conhecimento pedagógico do 
conteúdo, ou seja, se propõem a articular os conhecimentos específicos de química com os conhecimentos pedagógicos.

De forma geral, a tabela 4, mostra que os PPC priorizam a alocação da carga horária de PCC nas disciplinas específicas de Química, sendo que apenas no IFSudeste-43 essa lógica é diferenciada. Considerando que, no modelo de formação docente da racionalidade técnica a área específica não se articulava com a área pedagógica, a inserção de PCC em disciplinas específicas pode indicar que esses cursos assumem um modelo mais articulado de formação docente, mais próximo da racionalidade prática. Entretanto, as análises qualitativas das ementas dessas disciplinas apresentam contradições que podem ser entendidas pela análise dos conteúdos previstos nas ementas, pois mesmo inserindo as atividades de PCC em disciplinas específicas de química, as ementas não fazem menção aos conteúdos pedagógicos, ou referências à forma de como se desenvolve a PCC nessas disciplinas. Dessa forma, as contradições indicam a necessidade de avançar no estudo da PCC, a partir de outros instrumentos de coleta de dados como, por exemplo, entrevistas e observações de aulas. Um exemplo dessa forma de ementa abaixo:

IF-Sul-56: Química orgânica III: Planejamento de síntese orgânica. Interconversão de grupos funcionais. Grupos de Proteção. Análise retrossintética. Formação e reação de organoboranos e organosilanos. Estratégias sintéticas na preparação de produtos naturais biologicamente importantes. Prática de ensino. (2014, p. 65)

Tabela 4. Classificação das Áreas do Conhecimento Priorizadas no Desenvolvimento da PCC (continua)

\begin{tabular}{|c|c|c|c|c|c|c|c|c|c|}
\hline \multirow{2}{*}{ SIGLA PPC } & \multicolumn{2}{|c|}{$\begin{array}{l}\text { Disciplinas } \\
\text { Gerais }\end{array}$} & \multicolumn{2}{|c|}{$\begin{array}{l}\text { Disciplinas } \\
\text { Específicas }\end{array}$} & \multicolumn{2}{|c|}{$\begin{array}{r}\text { Disciplinas } \\
\text { Pedagógicas }\end{array}$} & \multicolumn{2}{|c|}{$\begin{array}{c}\text { Disciplinas } \\
\text { Articuladoras }\end{array}$} & \multirow{2}{*}{$\begin{array}{c}\text { Carga } \\
\text { Horária } \\
\text { Total } \\
\text { PCC } \\
\end{array}$} \\
\hline & Horas & $\%$ & Horas & $\%$ & Horas & $\%$ & Horas & $\%$ & \\
\hline IF-Centro-Oeste-4 & 140 & 25,93 & 250 & 46,30 & 40 & 7,41 & 110 & 20,37 & 540 \\
\hline IF-Centro-Oeste-6 & 94,7 & 23,58 & 233,6 & 58,17 & 0 & 0,00 & 73,3 & 18,25 & 401,6 \\
\hline IF-Centro-Oeste-7 & 80 & 21,05 & 220 & 57,89 & 40 & 10,53 & 40 & 10,53 & 380 \\
\hline IF-Nordeste-15 & 45 & 9,09 & 165 & 33,33 & 180 & 36,36 & 105 & 21,21 & 495 \\
\hline IF-Nordeste-17 & 100 & 21,28 & 220 & 46,81 & 120 & 25,53 & 30 & 6,38 & 470 \\
\hline IF-Nordeste-18 & 100 & 21,28 & 220 & 46,81 & 120 & 25,53 & 30 & 6,38 & 470 \\
\hline IF-Nordeste-19 & 100 & 21,28 & 220 & 46,81 & 120 & 25,53 & 30 & 6,38 & 470 \\
\hline IF-Nordeste-20 & 165 & 36,67 & 105 & 23,33 & 110 & 24,44 & 70 & 15,56 & 450 \\
\hline IF-Nordeste-22 & 100 & 21,28 & 220 & 46,81 & 120 & 25,53 & 30 & 6,38 & 470 \\
\hline IF-Nordeste-23 & 85 & 20,99 & 200 & 49,38 & 120 & 29,63 & 0 & 0,00 & 405 \\
\hline IF-Nordeste-24 & 60 & 14,46 & 150 & 36,14 & 115 & 27,71 & 90 & 21,69 & 415 \\
\hline IF-Nordeste-25 & 50 & 12,35 & 240 & 59,26 & 115 & 28,40 & 0 & 0,00 & 405 \\
\hline
\end{tabular}


Tabela 4. Classificação das Áreas do Conhecimento Priorizadas no Desenvolvimento da PCC (continuação)

\begin{tabular}{|c|c|c|c|c|c|c|c|c|c|}
\hline \multirow{2}{*}{ SIGLA PPC } & \multicolumn{2}{|c|}{$\begin{array}{c}\text { Disciplinas } \\
\text { Gerais }\end{array}$} & \multicolumn{2}{|c|}{$\begin{array}{l}\text { Disciplinas } \\
\text { Específicas }\end{array}$} & \multicolumn{2}{|c|}{$\begin{array}{r}\text { Disciplinas } \\
\text { Pedagógicas }\end{array}$} & \multicolumn{2}{|c|}{$\begin{array}{c}\text { Disciplinas } \\
\text { Articuladoras }\end{array}$} & \multirow{2}{*}{$\begin{array}{c}\text { Carga } \\
\text { Horária } \\
\text { Total } \\
\text { PCC }\end{array}$} \\
\hline & Horas & $\%$ & Horas & $\%$ & Horas & $\%$ & Horas & $\%$ & \\
\hline IF-Norte-38 & 50 & 13,51 & 90 & 24,32 & 110 & 29,73 & 120 & 32,43 & 370 \\
\hline IF-Sudeste-43 & 0 & 0,00 & 0 & 0,00 & 345 & 74,19 & 120 & 25,81 & 465 \\
\hline IF-Sudeste-45 & 24 & 5,88 & 42 & 10,29 & 72 & 17,65 & 270 & 66,18 & 408 \\
\hline IF-Sudeste-46 & 24 & 5,88 & 42 & 10,29 & 72 & 17,65 & 270 & 66,18 & 408 \\
\hline IF-Sudeste-47 & 120 & 30,00 & 185 & 46,25 & 70 & 17,50 & 25 & 6,25 & 400 \\
\hline IF-Sudeste-48 & 114 & 23,08 & 247 & 50,00 & 57 & 11,54 & 76 & 15,38 & 494 \\
\hline IF-Sudeste-49 & 114 & 27,59 & 299,25 & 72,41 & 0 & 0,00 & 0 & 0,00 & 413,25 \\
\hline IF-Sudeste-51 & 95 & 23,75 & 215 & 53,75 & 55 & 13,75 & 35 & 8,75 & 400 \\
\hline IF-Sudeste-52 & 28 & 6,90 & 280 & 68,97 & 14 & 3,45 & 84 & 20,69 & 406 \\
\hline IF-Sul-54 & 48 & 11,88 & 174 & 43,07 & 86 & 21,29 & 96 & 23,76 & 404 \\
\hline Total & 1736,7 & 18,20 & 4017,9 & 42,12 & 2081 & 21,81 & 1704,3 & 17,87 & 9539,85 \\
\hline
\end{tabular}

$\mathrm{Na}$ análise dos conteúdos dos PPC evidencia-se que, mesmo inserindo a PCC nas disciplinas de conteúdos específicos de química, as ementas não fazem menção aos conteúdos pedagógicos, ou menções de como se desenvolve a PCC nessas disciplinas, como é o caso da ementa da disciplina de Fundamentos da Química do IF-CentroOeste-4. Já nos cursos que optaram por criar disciplinas específicas para desenvolver a PCC, como no IF-Centro-Oeste-5, observa-se na ementa da disciplina Oficina de Prática Pedagógica em Química Geral, a integração entre os conteúdos específicos e pedagógicos e elementos do conhecimento pedagógico de conteúdo:

IF-Centro-Oeste-4: Fundamentos da Química - Matéria e energia. Elementos, compostos e misturas. Mol e massas molares. Cálculos estequiométricos e equações químicas. Soluções (modos de expressar a concentração de uma solução, Soluções e eletrólitos). Reações químicas (balanceamento; tipo e condições para ocorrência). Estrutura eletrônica dos átomos. Propriedades periódicas. Ligações químicas (ligações iônica e covalente). Eletronegatividade. Radioatividade. (2013, p. 32)

IF-Centro-Oeste-5: Oficina de Prática Pedagógica de Química Geral - Prática Pedagógica de Química Geral. Leitura, análise e discussão de artigos científicos e livros relacionados ao ensino de Química Geral. Discussão sobre a comunicação em público com ênfase na prática docente. Discussão de questões étnico-raciais. Produção de material didático relacionados ao ensino de Química Geral, com enfoque na produção de materiais alternativos e de baixo custo. Química e educação ambiental. (2017, p. 63)

Essa mesma falta de articulação entre os conhecimentos, que está expressa, nas ementas das disciplinas específicas de Química que desenvolvem a PCC é visualizada em disciplinas de formação pedagógica ou de formação humanística geral. Nesses casos percebe-se também falta de relação com a área específica, bem como a falta de descrição 
do desenvolvimento da PCC. É comum que essas disciplinas enfoquem somente o conhecimento pedagógico e não se articulem com o ensino de química ou de ciências. Como no caso abaixo da disciplina de Didática do IF-Nordeste-14. Entretanto, mesmo que com menor frequência, encontrou-se no PPC do IF-Sul-54 uma disciplina de Desenvolvimento Humano e Aprendizagem com uma ementa que é predominantemente pedagógica, mas que articula o seu conteúdo ao ensino de química:

IF-Nordeste-14: Didática: A Didática no seio das teorias pedagógicas. Tendências Pedagógicas Liberais [Tradicional, Progressivista, Não-Diretiva e Tecnicista]. Tendências Pedagógicas Progressistas [Libertadora, Libertária, Crítico-Social dos Conteúdos, Sociointeracionista]. Planejamento de ensino: perspectiva crítica, estratégias, etapas para elaboração. Saberes, competências e atitudes docentes. Competências didáticas para o trabalho docente. Procedimentos didáticos: elementos para o planejamento de ensino. Avaliação do processo ensino-aprendizagem. Interdisciplinaridade. Métodos e técnicas de ensino. Utilização adequada dos recursos instrucionais. (2010, p. 76)

IF-Sul-54: Desenvolvimento Humano e Aprendizagem - Estudo, análise e reflexão das teorias de Desenvolvimento Humano e Aprendizagem, com ênfase em: 1) Teorias do desenvolvimento humano e aprendizagem - DHA 2) Desenvolvimento físico, cognitivo e psicossocial e os processos de aprendizagem nas diversas fases do desenvolvimento humano, da concepção até a terceira idade; 3) Aplicações da teoria no contexto escolar e do ensino de Química. Produção de conhecimento em DHA. Desenvolvimento Tecnológico, criatividade e inovação em DHA. (2014, p. 48)

Nos 7 PPC que desenvolvem as atividades de PCC de modo híbrido, ou seja, tem a carga horária distribuída em diversas disciplinas da matriz curricular, mas também em algumas disciplinas específicas em que apenas a PCC é desenvolvida, apenas em um PPC não foi possível classificar a organização do conhecimento, pois não apresentaram as ementas no PPC. Nos demais se visualizou que as disciplinas articuladoras têm maior carga horária para desenvolver a PCC, seguida das disciplinas específicas de química, conforme pode ser visto na Tabela 5.

Tabela 5. Inserção da PCC nos Projetos Pedagógicos de Curso Híbridos

\begin{tabular}{|c|c|c|c|c|c|c|c|c|c|}
\hline \multirow{2}{*}{ SIGLA PPC } & \multicolumn{2}{|c|}{$\begin{array}{l}\text { Disciplinas } \\
\text { Gerais }\end{array}$} & \multicolumn{2}{|c|}{$\begin{array}{l}\text { Disciplinas } \\
\text { Específicas }\end{array}$} & \multicolumn{2}{|c|}{$\begin{array}{r}\text { Disciplinas } \\
\text { Pedagógicas }\end{array}$} & \multicolumn{2}{|c|}{$\begin{array}{c}\text { Disciplinas } \\
\text { Articuladoras }\end{array}$} & \multirow{2}{*}{$\begin{array}{c}\text { Carga } \\
\text { Horária } \\
\text { Total } \\
\text { PCC }\end{array}$} \\
\hline & Horas & $\%$ & Horas & $\%$ & Horas & $\%$ & Horas & $\%$ & \\
\hline IF-Centro-6 & 94,7 & 23,58 & 233,6 & 58,17 & 0 & 0,00 & 73,3 & 18,25 & 401,6 \\
\hline IF-Norte-38 & 50 & 13,51 & 90 & 24,32 & 110 & 29,73 & 120 & 32,43 & 370 \\
\hline IF-Sudeste-45 & 24 & 5,88 & 42 & 10,29 & 72 & 17,65 & 270 & 66,18 & 408 \\
\hline IF-Sudeste-46 & 24 & 5,88 & 42 & 10,29 & 72 & 17,65 & 270 & 66,18 & 408 \\
\hline IF-Sudeste-52 & 28 & 6,90 & 280 & 68,97 & 14 & 3,45 & 84 & 20,69 & 406 \\
\hline IF-Sul-58 & 92 & 18,55 & 232 & 46,77 & 0 & 0,00 & 172 & 34,68 & 496 \\
\hline Total & 234,7 & 13,70 & 549,6 & 32,07 & 144 & 8,40 & 785,3 & 45,83 & 1713,6 \\
\hline
\end{tabular}


Considera-se que o conteúdo específico tem um papel fundamental na formação docente, pois o professor em sua prática pedagógica articula esse conhecimento aos demais para ensinar. Portanto, a competência pedagógica passa pelo conhecimento da área específica e a constituição do conhecimento pedagógico do conteúdo passa pela profunda articulação entre conhecimento específico, conhecimento pedagógico e experiência docente. Assim, compreende-se que "[...] a competência pedagógica está atrelada a um conteúdo específico que é transformado, levando em consideração as dificuldades dos alunos com esse conteúdo, o contexto, as estratégias instrucionais, os modos de avaliação, o currículo, os objetivos, etc.” (Fernandez, 2015, p. 504).

Diante das considerações colocadas, percebe-se que os PPC apresentam os conteúdos de formas diferentes nas ementas, sendo que, ao propor disciplinas específicas para a PCC, conseguem esclarecer as articulações entre os campos do conhecimento necessários à constituição do conhecimento pedagógico de conteúdo, enquanto que ao inserir a PCC de forma diluída não explicitam o lugar da prática como conhecimento, nem as articulações entre conhecimento específico e pedagógico. Ainda, pode-se observar a necessidade de tornar explícitas as articulações entre os conhecimentos e o desenvolvimento da PCC nos currículos, independentemente do formato adotado para inseri-la nos cursos de Licenciatura em Química. Dessa forma, mesmo que seja possível visualizar alterações curriculares nesses cursos, que os colocam em uma perspectiva da racionalidade prática, a dificuldade para esclarecer a PCC nos PPC pode indicar que a alocação dessas práticas nos cursos foi apenas para cumprir as normativas para formação docente. Portanto, uma aproximação dos contextos em que se desenvolvem essas atividades, com outros instrumentos de coleta e análise de dados poderá mostrar as permanências da racionalidade técnica e as possibilidades da racionalidade prática.

\section{Profissionalização Docente como Princípio do Campo da Formação de Professores na Prática como Componente Curricular}

Na análise das concepções sobre a PCC, diversos elementos conceituais do campo da formação de professores são expressos e assumidos nos PPC. As concepções que aparecem com maior frequência são a prática profissional, a articulação de conhecimentos específicos e pedagógicos, a relação teoria e prática e a relação entre a instituição e a Educação Básica. Já entre as concepções com menor frequência a interdisciplinaridade e a pesquisa como princípio educativo. Para fins de análise, optou-se por desenvolver a concepção de profissionalidade, pelas profundas articulações e contradições que ela expressa nos PPC e sobre a compreensão da PCC. Além disso, destaca-se que a prevalência da profissionalização docente nos PCC traz um alinhamento dos mesmos com uma perspectiva da racionalidade prática.

A compreensão da PCC como prática profissional se expressa em passagens dos PPC, sendo a concepção utilizada com maior frequência. A forma de expressar essa concepção está no texto do PPC que explica as concepções e práticas de PCC, bem como na construção das disciplinas que desenvolvem especificamente a PCC. Desse modo, 
encontraram-se elementos textuais dessa concepção, bem como disciplinas da matriz curricular que desenvolvem a PCC e tem em seu nome a expressão Prática Profissional. A profissionalidade faz parte do campo da formação docente, pois ao considerar que $o$ professor aprende e constrói sua profissionalidade alguns conhecimentos precisam ser desenvolvidos por meio de alguns princípios.

Nos PPC a profissionalização aparece em contextos escritos diversos e com significados próprios. Portanto, visualiza-se nos trechos abaixo que os PPC assumem a PCC como forma de aproximar o licenciando do contexto sociocultural pedagógico da profissão docente:

IF-Centro-Oeste-1: Esta correlação teoria e prática é essencial para a formação do futuro professor no sentido de fomentar uma profissionalidade que tem como exigência um fecundo movimento entre saber e fazer na construção de significados para a gestão, a administração e a resolução de situações-problemas próprias do ambiente educacional. (2014, p. 31)

IF-Sudeste-41: A prática profissional apresentada aqui está distante da concepção, considerada verdadeira em outras épocas, de que a prática representaria o saber-fazer, ou o simples laboral. Longe de constituir-se num receituário de fórmulas, caracterizase mais especificamente como a oportunidade de leitura e análise da realidade atual na perspectiva do ousar a construção do novo, o que, em alguns aspectos nos obriga à adoção de procedimentos de desconstrução da estrutura existente, fechada em seus engessados conceitos, de modo que o universo da ação escolar possa ser de fato, locus em que as diversas culturas interajam e onde se estabeleçam redes de conhecimento. E tudo isto só se efetiva com a adoção de metodologias diferenciadas e, efetivamente, na mudança do perfil de educador. (2014, p. 28-29)

Outra forma de apresentar a profissionalização docente aparece nos PPC de forma entrelaçada ao estágio supervisionado e com enfoque na realidade escolar. Percebe-se que não há uma diferenciação entre estágio e PCC. O Parecer 28 de 2001 discute a diferença entre PCC e estágio supervisionado e explicita que a PCC está relacionada aos diversos níveis e modalidades da educação formal e informal e sua diferença com o estágio é a relação pedagógica que este pressupõe entre "[...] um profissional reconhecido em um ambiente institucional de trabalho e um aluno estagiário" (Parecer n. 28, 2001, p.10). Essa normativa também reforça que o estágio supervisionado exige o "[...] exercício direto in loco, seja pela presença participativa em ambientes próprios de atividades daquela área profissional, sob a responsabilidade de um profissional já habilitado" (Parecer n. 28, 2001, p.10). Conforme pode ser constatado nos excertos a seguir:

IF-Nordeste-16: A Prática de Ensino e o Estágio Curricular Supervisionado, ambos com carga horária de 400 horas, perfazendo um total de 800 horas, são entendidos como o tempo de aprendizagem da prática da docência. É um momento de formação profissional seja pelo exercício direto in loco, seja pela presença participativa no ambiente escolar, seja na reflexão e avaliação de sua prática, sob a responsabilidade de um profissional já habilitado e de um professor orientador. Compreende atividades 
desenvolvidas nas escolas de educação básica da região, podendo ocorrer ainda nesta Instituição, em especial no ensino médio, propiciando ao aluno uma vinculação entre teoria e prática e uma articulação com a sala de aula, além do desenvolvimento de saberes profissionais, dando uma visão mais abrangente da atuação do Licenciado em Química. (2013, p. 37)

IF-Nordeste-21: O desenvolvimento profissional e a inserção do discente no mundo do trabalho exigem competências pessoais e técnicas que vão além da formação regular em sala de aula, que deve ser vivenciadas ao longo do curso, em espaços educativos escolares e não escolar, garantindo a inserção do aluno no contexto profissional e totalizando 400 horas. Neste projeto do curso de Licenciatura em Química, a Prática Profissional está presente desde o início do curso, permeando toda a formação do professor. (2010, p. 66)

A forma de desenvolver a PCC está expressa em diversos PPC. Por meio dela se explicitam modos de tornar as articulações entre os campos do conhecimento visíveis e ao mesmo tempo atender as normativas para a formação docente, não confundindo os momentos de PCC e de estágio supervisionado. Entre as estratégias de desenvolvimento das PCC investigadas, percebe-se que elas podem ser realizadas sem que o licenciando esteja atuando em sala de aula, como no estágio, mas que ao mesmo tempo tem o espaço escolar como objeto de reflexão. Destacam-se entre as estratégias, atividades que pensam o ensino de química e ciências e promovem a discussão sobre os conteúdos específicos da química nas diretrizes curriculares para a Educação Básica e a elaboração de materiais didáticos. Portanto, nesses casos, constatam-se possibilidades de desenvolvimento do conhecimento pedagógico de conteúdo que, conforme Shulman (2005), é o conhecimento próprio da docência que articula conteúdos específicos e pedagógicos.

Destaca-se que ao adotar a profissionalização docente como concepção os PPC analisados se alinham com a racionalidade prática e o modelo do profissional reflexivo, conforme discutidos por Cunha (2013) e Contreras (2012). Portanto, as normativas para a formação docente impactam a construção dos PPC e tem fortalecido a mudança curricular do modelo do especialista técnico ou racionalidade técnica para o profissional reflexivo ou racionalidade prática.

Nessa perspectiva visualiza-se que há um alinhamento entre as normativas para formação docente, os PPC dos cursos analisados e as propostas para o Ensino de Ciências da Natureza da Base Nacional Curricular Comum (BNCC) que evidenciam a racionalidade prática como um modelo que vem se colocando como predominante nas normativas e políticas para a formação docente e, consequentemente para a Educação Básica.

De acordo com Franco, e Munford (2018) a BNCC se consolida a partir de uma concepção de currículo como organizador da prática pedagógica. Assim, nesse documento é proposto um conjunto de competências e habilidades estabelecido e estabilizado que colocam à margem do processo pedagógico os professores e estudantes. Nessa perspectiva a BNCC desconsidera os diferentes contextos sociais e condicionantes institucionais existentes na realidade brasileira. 
Visualiza-se que as normativas para a formação docente e a BNCC se colocam com a mesma compreensão dos PPC analisados: a racionalidade prática. Isso significa que esses cursos assumem um projeto formativo do professor de Química que rompe com a racionalidade técnica, ou $3+1$, e se aproxima de um modelo de profissionalização da racionalidade prática. De tal modo, considera-se que os cursos de Licenciatura em Química dos Institutos Federais, de diferentes formas, assumem um modelo de formação de professores em reciprocidade com o campo em que se insere. Logo, ainda é preciso avançar na formação docente para a constituição de um modelo de formação docente intelectual crítico, conforme proposto por Contreras (2012).

\section{Considerações Finais}

$\mathrm{Na}$ apresentação do artigo algumas questões iniciais foram postas e ao longo de todo texto foram respondidas: Como a prática como componente curricular se insere nos projetos pedagógicos de curso das licenciaturas em química dos Institutos Federais? Quais as concepções da prática como componente curricular se destacam nesses projetos pedagógicos de curso? Quais conhecimentos são priorizados nas disciplinas que desenvolvem atividades de PCC? Quais princípios do campo da formação docente são assumidos na proposta curricular das atividades de PCC?

Em relação às formas de inserir a PCC com PPC dos cursos de Licenciatura em Química, evidenciou-se neste artigo que há três formas de organização curricular nos cursos ofertados nos Institutos Federais de Educação no Brasil. A primeira forma de organização distribui as 400 horas de PCC ao longo de diferentes disciplinas, sendo a PCC uma porcentagem da carga horária da disciplina. A segunda forma de organização curricular apresenta disciplinas específicas para desenvolver a PCC, ou seja, as disciplinas têm toda a sua carga horária para essas atividades. Por sua vez, essas disciplinas apresentaram nomenclaturas diversas como, por exemplo, instrumentação, prática pedagógica, oficina de prática pedagógica, prática de ensino, prática educativa, etc. Por fim, a terceira forma denominada híbrida, que contempla as duas formas anteriores.

As concepções da PCC desenvolvidas nos PPC são diversas e mostram que as interpretações das normativas para a formação docente estão ligadas aos contextos em que os cursos são desenvolvidos. Portanto, embora tenha sido possível identificar a presença da PCC em todos os PPC, visualiza-se que na matriz curricular, nas ementas e nos textos sobre essa prática há a carência de explicitações sobre as formas de integralização da PCC. Considerando a análise realizada, defende-se, assim como Almeida (2016), a não padronização das atividades de PCC, mas a necessidade de explicitá-las de forma mais clara nos PPC.

Destaca-se que as articulações entre os conhecimentos específicos e pedagógicos, próprias do conhecimento pedagógico de conteúdo, estão fortemente presentes nas disciplinas consideradas como articuladoras. Dessa forma, ao organizar disciplinas que têm como objetivo desenvolver atividades de PCC na integridade de sua carga horária, independente de ser no modelo curricular que tem disciplinas específicas para PCC ou 
no modelo híbrido que tem 400 horas de PCC, ao longo de diferentes disciplinas e em disciplinas específicas, visualiza-se toda a potencialidade das atividades de PCC para a formação docente. Por outro lado, evidencia que nas demais formas de inserir a PCC nos cursos de Licenciatura em Química as horas podem estar evidenciadas de forma burocrática, apenas para atender a legislação.

Ao mesmo tempo, a forma de organizar a PCC nas disciplinas, e os diferentes conhecimentos que elas priorizam nos cursos de Licenciatura em Química, demonstra a grande contribuição da área de Química para essas atividades em carga horária. A partir dessa constatação, compreende-se que os cursos analisados organizam-se de modo a assumir o modelo curricular de licenciatura a partir da racionalidade prática. Isso significa que esses cursos assumem um projeto formativo do professor de Química que rompe com a racionalidade técnica, ou $3+1$, e se aproxima de um modelo de profissionalização. De tal modo, considera-se que os cursos de Licenciatura em Química dos Institutos Federais, de diferentes formas, assumem um modelo de formação de professores em sintonia com o campo em que se insere, pois além da profissionalização visualizou-se a busca pela construção de currículos com pesquisa, interdisciplinaridade e articulação de conhecimentos específicos e pedagógicos. Nesse sentido, ainda é preciso avançar na formação docente para a constituição de um modelo de formação docente intelectual crítico, conforme proposto por Contreras (2012).

Por fim, as constatações desse artigo são provisórias e permitem evidenciar a necessidade de aprofundamento da temática utilizando outros instrumentos de coleta de dados, para além da análise documental. Dessa forma, seria possível, por exemplo, elucidar como estão sendo desenvolvidas as PCC, nos cursos que distribuem sua carga ao longo de diversas disciplinas do curso, pois, como a análise evidenciou, nesses casos, as ementas carecem de informações para explicitar essas relações.

Para estudos com outras metodologias de pesquisa, para além da análise documental proposta por este artigo, reconhece-se a fragilidade dos referenciais teóricos que se inserem na racionalidade prática, como é o caso de Shulman (2005), pois ao discutir as concepções da PCC a partir das ideias, das práticas pedagógicas e dos agentes sociais é necessário utilizar referenciais que discutam as questões políticas e sociais relacionadas à formação docente.

\section{Referências}

Almeida, S. (2016). A prática como componente curricular nos cursos de formação de professores de química no estado de Goiás. (Dissertação de Mestrado em Educação em Ciências e Matemática). Universidade Federal de Goiás, Goiânia.

Bourdieu, P. (1989) O poder simbólico. Rio de Janeiro: Bertrand.

Decreto-Lei n. 1.190, de 04 de abril de 1939 (1939). Dá organização à Faculdade Nacional de Filosofia. Diário Oficial da União. Rio de Janeiro, RJ: Ministério da Educação e Saúde Pública. 
Contreras, J. (2012) A autonomia de professores. São Paulo: Cortez.

Cunha, M. I. (2013) O tema da formação de professores: trajetórias e tendências do campo na pesquisa e na ação. Revista Educação e Pesquisa, 39(3), 609-624. https://doi. org/10.1590/S1517-97022013005000014

Diniz-Pereira, J. E. (2013). A construção do campo da pesquisa sobre formação de professores. Revista da FAEEBA - Educação e Contemporaneidade, 22(40), 145-154.

Dourado, L. F. (2015). Diretrizes curriculares nacionais para a formação inicial e continuada dos profissionais do magistério da educação básica: concepções e desafios. Educação e Sociedade. 36(131), 299-324.

Estevão, C. (2011) Formação, gestão, trabalho e cidadania: Contributos para uma sociologia crítica da formação. Educação e Sociedade, 22(77), 185-206.

Fernandez, C. (2015) Revisitando a base de conhecimentos e o conhecimento pedagógico do conteúdo (PCK) de professores de ciências. Revista Ensaio, 17(2), 500-528.

Flick, U. (2009). Introdução à pesquisa qualitativa. Porto Alegre: Artmed, 2009.

Franco, L. G., \& Munford, D. (2018). Reflexões sobre a Base Nacional Comum Curricular: um olhar da área de Ciências da Natureza. Revista Horizontes, 36(1), 158-170. https:// doi.org/10.24933/horizontes.v36i1.582

Gil, A. C. (2008). Métodos e técnicas de pesquisa social. São Paulo: Atlas, 2008.

Kasseboehmer, A. C., \& Farias, S. A. (2012). Conteúdos das Disciplinas de Interface Atribuídos a Prática como Componente Curricular em Cursos de Licenciatura em Química. Alexandria: Revista de Educação em Ciência e Tecnologia, 5(2), 95-123.

Marcelo, C. G. (1998) Pesquisa sobre formação de professores: o conhecimento sobre aprender a ensinar. Revista Brasileira de Educação, (9), 51-75.

Marcelo, C. G. (1999) Formação de professores: para uma mudança educativa. Porto: Editora Porto.

Minayo, M. C. S. (2015) Pesquisa social: teoria, método e criatividade. Petrópolis: Vozes.

Mohr, A., \& Pereira, B. (2017) Origem e Contornos da Prática como Componente Curricular. In A. Mohr, \& H. G. Wielewicki. (Org.) Prática como componente curricular: que novidade é essa 15 anos depois? (pp. 19-38). Florianópolis: NUP/CED/UFSC.

Nóvoa, A. (1991). Profissão professor. Porto: Editora Porto.

Parecer n. 28 de 2001. (2001). Dá nova redação ao Parecer CNE/CP 21/2001, que estabelece a duração e a carga horária dos cursos de Formação de Professores da Educação Básica, em nível superior, curso de licenciatura, de graduação plena. Diário Oficial da União. Brasília, DF: Ministério da Educação. 
Parecer n. 15 de 2005. (2005). Solicitação de esclarecimento sobre as Resoluções CNE/ $\mathrm{CP} \mathrm{n}^{\circ}$ s 1/2002, que institui Diretrizes Curriculares Nacionais para a Formação de Professores da Educação Básica, em nível superior, curso de licenciatura, de graduação plena, e 2/2002, que institui a duração e a carga horária dos cursos de licenciatura, de graduação plena, de Formação de Professores da Educação Básica, em nível superior. Diário Oficial da União. Brasília, DF: Ministério da Educação.

Real, G. C. M. (2012) Prática como Componente Curricular: o que isso significa na prática? Educação e Fronteiras On-Line. 2(5), 48-62.

Resolução n. 01 de 2002 (2002). Institui Diretrizes Curriculares Nacionais para a Formação de Professores da Educação Básica, em nível superior, curso de licenciatura, de graduação plena. Diário Oficial da União. Brasília, DF: Ministério da Educação.

Resolução n. 02 de 2002. (2002). Institui a duração e a carga horária dos cursos de licenciatura, de graduação plena, de formação de professores da Educação Básica em nível superior. Diário Oficial da União. Brasília, DF: Ministério da Educação.

Resolução n. 02 de 2015. (2015). Define as Diretrizes Curriculares Nacionais para a formação inicial em nível superior (cursos de licenciatura, cursos de formação pedagógica para graduados e cursos de segunda licenciatura) e para a formação continuada. Diário Oficial da União. Brasília, DF: Ministério da Educação.

Resolução n. 03 de 2018. (2015). Altera o Art. 22 da Resolução CNE/CP nº 2, de $1^{\circ}$ de 2015, que define as Diretrizes Curriculares Nacionais para a formação inicial em nível superior (cursos de licenciatura, cursos de formação pedagógica para graduados e cursos de segunda licenciatura) e para a formação continuada. Diário Oficial da União. Brasília, DF: Ministério da Educação.

Saviani, D. (2009). Formação de professores: aspectos históricos e teóricos no contexto brasileiro. Revista Brasileira de Educação, 14 (40), 143-145.

Shulman, L. S. (2005). Conocimiento y enseñanza: fundamentos de la nueva reforma. Revista de currículum y formación del profesorado, 9(2), 1-30.

Triviños, A. N. S. (1987). Introdução à pesquisa em ciências sociais: a pesquisa qualitativa em educação. São Paulo: Atlas.

Valério, M. (2017). Autonomia dos professores. Educar em Revista, (66), 327-332. https://doi.org/ DOI/10.1590/0104-4060.52325 
Priscila Juliana da Silva

${ }^{\circ}$ https://orcid.org/0000-0002-1672-6143

Instituto Federal de Santa Catarina Jaraguá do Sul, Santa Catarina, Brasil

priscila.silva@ifsc.edu.br

Orliney Maciel Guimarães

https://orcid.org/0000-0003-4762-4884

Universidade Federal do Paraná

Departamento de Química

Curitiba, Paraná, Brasil

orli.guimaraes@gmail.com

Submetido em 28 de fevereiro de 2019 Aceito em 30 de setembro de 2019

Publicado em 04 de novembro de 2019 